\title{
SEMILLA OCEÂNICA: TEATRALIZANDO SOBRE GÊNERO E DIREITOS DAS CRIANÇAS NO CHILE
}

\author{
Dóris Regina Marroni Furini ${ }^{1}$
}

\section{Resumo}

Este texto é um exercício de contar a experiência de trabalho com Teatro do Oprimido em uma ilha no Chile. Em um primeiro momento disponho informações acerca da Ilha

Robinson Crusoè, sua população e alguns traços culturais, para compreender onde realizei o trabalho. A seguir, explicito os fundamentos do Teatro do Oprimido, bem como algumas referências sobre gênero e direitos das crianças. Na sequência, relato como ocorreu o processo de construção do grupo e da peça. Ao finalizar procuro refletir porque esta experiência foi tão significativa para nós todos/as.

Palavras-chave: teatro do oprimido, gênero, direitos das crianças.

\section{Abstract}

This paper is an exercise on telling the experience of working with Theatre of the Oppressed in an island, in Chile. At first, it supplies information about the Robinson

Crusoe Island, its population and some cultural traits, to make clear where the work happened. Then it explains the foundations of Theatre of the Oppressed, as well as some references on gender and children's rights. Further, there

is a report about the the group building process and the theatre devising process. At the end I try to reflect why this experience was so significant for all of us / them.

Keywords: theatre of the oppressed, gender, children's rights. 


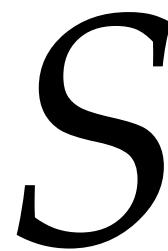

emilla Oceânica foi o nome definido pelos componentes do grupo de teatro, formado a partir do curso de Teatro do Oprimido que realizei entre os meses de setembro e novembro de 2009, com habitantes da Ilha Robinson Crusoè Arquipélago de Juan Fernandez, no Chile. O nome escolhido pelo grupo expressa um pouco do sentimento dos habitantes desta ilha oceânica: estão distantes de tudo e são pequenos aos olhos dos governantes, contudo têm possibilidade de crescer, fortalecer-se e romper barreiras.

Foi por meio de uma amiga próxima que cheguei a um colega de profissão - psicólogo - que estava trabalhando e morando em lugar "paradisíaco e mui lejos", uma ilha, conhecida pelo curioso nome de Robinson Crusoé 2 . Feito o contato e o convite para realizar um trabalho de teatro com crianças e jovens na ilha, comecei a viagem, em agosto de 2009. Desde Santiago, no Chile, esperei por uma semana para que o as condições climáticas do oceano nada Pacífico permitissem e o piloto autorizasse o vôo para a ilha, em um avião de seis lugares, com duração de 3 horas. Ao me aproximar da ilha, compreendi de imediato porque ela foi declarada Reserva Mundial da Biosfera, pela UNESCO, uma natureza exuberante: Imensos paredões rochosos, esculpidos pela lava de um vulcão extinto e colônias de lobos marinhos faziam a recepção, Depois disso, há que se navegar, desde o aeródromo até o pueblo, num bote, por mais três horas.

Por essa dificuldade de acesso, a ilha é considerada um dos cinco lugares mais isolados do planeta. Atualmente vivem nela 700 pessoas, divididas entre

1 Psicóloga, Doutora em Educação (UFRGS/2009), Multiplicadora do Teatro do Oprimido pelo Centro do Teatro do Oprimido do Rio de Janeiro. E-mail: dorisfurini@hotmail.com

2 A ilha foi descoberta 1574 pelo navegador espanhol Juan Fernández. A partir do relato do marinheiro Alexander Selkirk, que entre os anos 1704-1708 sobreviveu isolado ao desterro nesta ilha, o escritor inglês Daniel Defoe escreveu, em 1719 o famoso romance "A vida e aventuras de Robinson Crusoè". A épica saga de Selkirk, imortalizada nas incríveis aventuras do personagem literário, foi suficiente, que se efetuasse a troca de nome de Masatierra, para Robinson Crusoè, em 1966. nativos e pessoas de outras regiões do país que decidiram viver na ilha, seja para trabalhar, para viver em segurança, ou para realizar o sonho de viver em uma pequena comunidade. Sua economia fundamenta-se na pesca da lagosta e no turismo ecológico/rural, que começa a ser uma atividade valorizada entre os seus habitantes. Existe na ilha uma administração pública, uma escola básica e de ensino médio, um posto de saúde para atendimento emergencial e um serviço de atendimento psico-social. Foi por este serviço e pelo Comitê de Promoção dos direitos das crianças e adolescentes COPRODE - que fui convidada a fazer o curso de Teatro do Oprimido com crianças e jovens.

\section{Teatralizando sobre gênero e direitos das crianças no Chile}

Desde minha chegada na ilha, além do desafio da comunicação - em espanhol chileno - outros desafios surgiram: a direção da escola não permitiu que falássemos com os estudantes, por considerar perda de tempo uma atividade como o teatro. Aos poucos compreendi que mesmo sendo uma comunidade muito pequena, nesta ilha, havia os mesmos problemas sociais e políticos que enfrentamos em outras cidades, como por exemplo, o embate entre uma postura progressista, de esquerda e o autoritarismo que encontra-se muito arraigado culturalmente, bem como militarismo que persiste, fruto dos tempos da ditadura chilena. Lugar chico, infierno largo, me diziam os moradores. Reconhecer que o paraíso não era ali, foi um momento importante e o ponto de partida para, superando pré-conceitos, conhecer de fato as possibilidades dos habitantes da ilha.

Após um período de aproximação com a comunidade, começamos o trabalho com um grupo de 21 moradores, incluindo

3 As oficinas aconteciam três vezes por semana e tinham duração de três a quatro horas. Além das oficinas realizamos perfornance nas ruas e no Museu, a fim de presentear a comunidade com poesias e mobilizá-la para o teatro. 
crianças, jovens e adultos ${ }^{3}$. Por ser um grupo misto, a troca entre as gerações foi intensa e em muitos momentos exigiu de todos re-conhecimento dos limites de si e do outro. O princípio da dialogicidade foi a tônica dos encontros e, neste sentido, ao referir-se à perspectiva de trabalho com o Teatro do Oprimido, afirma Boal:

O Teatro do Oprimido se baseia no princípio de que todas as relações humanas deveriam ser de natureza dialógica: entre homens e mulheres, raças, famílias, grupos e nações, sempre o diálogo deveria prevalecer. $\mathrm{Na}$ realidade, em sociedades de consumo e mercado como a nossa, os diálogos têm a tendência a se transformarem em monólogos que terminam por criarem a relação Opressores-Oprimidos. Reconhecendo esta realidade, o princípio fundamental do Teatro do Oprimido é o de ajudar e promover a restauração do Diálogo entre os seres humanos. Desta maneira, o teatro do oprimido torna-se libertador de ambos, do oprimido e do opressor (BOAL, 1973, p.44).

É importante demarcar que o termo "oprimido", que qualifica esta metodologia de teatro, se refere aos indivíduos ou grupos que são, social, cultural, política, econômica, racial ou sexualmente despossuídos do seu direito ao Diálogo ou, de qualquer forma, diminuídos no exercício desse direito. Diálogo é aqui definido como o livre intercâmbio com os Outros, individual ou coletivamente; como a livre participação na sociedade humana entre iguais; o respeito às diferenças e pelo direito de ser respeitado

Neste sentido, o Teatro do Oprimido é mais que uma metodologia de teatro, é um movimento estético mundial, realizado e difundido em mais de 70 países, nas suas maisdiferentesvertentes:social, pedagógica,

4 Augusto Boal (Rio de Janeiro, 1931-2009). Foi diretor, autor teórico e referência internacional do teatro brasileiro. Principal liderança do Teatro de Arena de São Paulo nos anos 60. Criador do teatro do oprimido, metodologia internacionalmente conhecida que alia teatro ação social. Foi fundador e coordenador do Centro de Teatro do Oprimido/ CTO-Rio, até sua morte em 2009. Site: [www.ctorio.org.br] artística, política e psicoterápica. Idealizado e estruturado pelo teatrólogo Augusto Boal ${ }^{4}$ o teatro do oprimido é um instrumento valioso também porque muda a concepção na produção da arte, na medida em que, a população assume os meios da produção na elaboração da arte. Assim, a população passa de mero consumidor para produtor da arte e da cultura com uma produção que se realiza a partir das suas próprias concepções e referencias da sua comunidade, contribuindo para o fortalecimento e valorização da sua cultura regional (www.ctorio.org.br).

Foi com o princípio da relação dialógica e da comunidade como produtora de arte e cultura, que o trabalho foi desenvolvido. Neste percurso o processo de escolha da temática da peça a ser construída pelo grupo foi denso e intenso. Dentre algumas temáticas que emergiram a partir da dinâmica de quebra de repressão, o grupo definiu a história de abuso sexual contra meninas para ser transformada em peça. A emergência deste tema foi uma surpresa para mim, pois desconhecia esta realidade da ilha. Desde minha chegada, eram os relatos de opressão no trabalho e na escola, o que mais escutava na comunidade, e imaginava que uma destas seria a temática definida pelo grupo, para a peça de teatro fórum (o que para mim, sozinha na coordenação dos trabalhos, seria mais indicado e menos assustador, na verdade). Apesar de algumas tentativas minhas de "convencê-los" a mudar de temática, o grupo mantinha a proposta, afirmando que este era o momento de discutir o tema, pois apesar de ser uma situação recorrente na ilha, nunca houve denúncia formal. Após noites de insônia e dias de discussão e questionamentos com o grupo, era eu quem estava convencida de que este seria nosso tema de trabalho.

A partir da história de uma das jovens do grupo, que foi abusada na infância, discutimos essa situação trazendo, tanto o contexto da cultura local, das relações de poder e de autoritarismo presentes na comunidade, quanto buscando referencias para compreender historicamente o 
silêncio imposto às crianças e às mulheres, bem como a necessidade de cada vez mais efetivarmos percursos de expressões estéticas e narrativas femininas, que superem a perspectiva do corpo-paraabuso, corpo-objeto para consumo, considerando que "é no corpo feminino que se trava hoje, mais do que no masculino, o embate entre os hábitos ancestrais e a defesa dos direitos humanos fundamentais. Essa condição comporta ilusões, feridas, contradições e uma busca urgente de significados" (ProjetoMadalena, www.ctorio. org.br). Neste percurso, necessariamente emergiram questões referente a gênero, onde se considerem a relação entre social e biológico, como afirma Louro (1994, p. 40): "com referência a gênero, além das diferenças físicas realmente existentes e observáveis, a imbricação do social e do biológico está muito mais enraizada culturalmente e portanto são muito maiores as possibilidades de se operar a naturalização do social e a socialização do biológico".

Insistir sobre o caráter cultural e social das relações de gênero significa considerar que além de uma categoria biológica, o gênero também é uma categoria histórica. Ou seja, o fazer-se homem ou mulher não é um dado resolvido no nascimento, pelas características biológicas de cada um, mas construído através de práticas sociais masculinizantes ou feminilizantes de acordo com as diferentes concepções presentes em cada sociedade. Portanto, há de se colocar aquilo que Auad (2006, p. 17) chama de "óculos de gênero para enxergar a realidade".

Neste sentido cabe trazer a discussão de Scott (1995, p. 86): o núcleo essencial da definição de gênero baseia-se na conexão integral entre duas proposições: o gênero é um elemento constitutivo das relações sociais baseadas nas diferenças percebidas entre os sexos, e o gênero é uma primeira forma de significar relações de poder.

O mesmo movimento de desnaturalização que realizamos no âmbito das relações de poder entre gêneros, buscamos realizar no que se refere ao abuso sexual contra meninas na ilha. Isto exigiu olhar para esta situação a luz também da perspectiva dos direitos das crianças no Chile. Percebe-se então, a existencia de uma legislação ambigua:

No obstante, transcurridos 16 años desde la ratificación de la Convención de los Derechos del Niño, las proyecciones originales en cuanto a la necesidad de desmantelar el sistema "tutelar" tradicional para crear un sistema de protección integral de derechos todavía no se han cumplido. Así, en el plano de la regulación jurídica, la Ley de Menores No16.618 (anterior a la Convención no sólo por ser una Ley que data del año 1967, sino porque en rigor dicha ley reúne en un nuevo cuerpo las modificaciones hechas a la ley original de 1928) todavía continúa vigente, y es incierto el destino de su supuesto reemplazo a través de una Ley de Protección de derechos, cuyo proyecto, presentado al Ejecutivo durante el año 2004, se encuentra estancado, y cuyo contenido no garantiza todo lo necesario de plasmar legislativamente en aras de una adecuación plena a la Convención.(DELGADO-SCHENK; PETER, 2007, p. 63).

Este contexto jurídico encontrase materializado também em ações sócio-educativas que ora confirmam a Convenção, reafirmando os direitos das crianças, ora expressam o caráter tutelar e assistencialista da Ley de Menores. Afirma o documento:

De esta forma, conviven actualmente en Chile normas, criterios, instituciones y mecanismos provenientes de la era previa a la Convención sobre los Derechos del Niño, con una clara inspiración tutelar, y normas y criterios posteriores que han intentado dar aplicación a la perspectiva de derechos a propósito de variados temas relacionados con la infancia, sin que se haya logrado aun una adecuación sustantiva a dicha perspectiva. Por ello, el modelo vigente es híbrido, y se podría decir que el país sigue en una fase de transición que requerirá todavía de muchos y profundos 
ajustes y reformas que estructuren un verdadero sistema integral de protección a los derechos de los niños (DELGADO-SCHENK; PETER, 2007, p. 66).

Foi a convicção de que é necessário reafirmar a condição de sujeitos de direitos das crianças, bem como romper o silêncio e as opressões a que estão submetidas meninas e mulheres, que garantiu a participação intensa de todo o grupo no trabalho. No entanto, a escolha por esta temática fez com que nos dedicássemos por um tempo significativo a pensar como trazer este tema para a cena, de modo a mobilizar a comunidade para discutir a questão sem com isso criar mais situações de opressão e violência nas famílias e com a comunidade, pois todos do grupo moravam na ilha, menos eu. Este era um cuidado que todo o tempo me mantinha atenta: eu era a estrangeira na comunidade e não estava ali para dizer como deveriam ser as coisas, para trazer a "verdade" sobre o que quer que fosse e depois ir embora. Ao contrário, minha posição sempre foi de quem aprende-quando-ensina, sendo o grupo a referencia para o que iríamos fazer.

A elaboração do roteiro da peça foi um processo intenso de criação do grupo e, coletivamente, encontramos uma alternativa para tratar da temática:faríamos um paralelo com a questão da pesca da lagosta, atividade de subsistência na ilha. Por ser parte da cultura local, todos os moradores sabem que lagostas pequenas não devem consumidas, e sim protegidas. Deste modo, a trama ocorreu no fundo do mar e contou a historia de uma lagosta pequena, que foi "devorada" por um polvo. Omesmo critério usamos na escolha do título - una mirada a las profundidades -, que fazia alusão às profundezas do mar, também poderia ser entendido do ponto de vista do abuso sexual com as crianças na ilha. Do mesmo modo que o roteiro, cenário, figurino e trilha sonora, foram construídos pelogrupo, entretantocontouse com envolvimento da comunidade, pois todo $\mathrm{o}$ material dramático foi produzido a partir dos recursos nela disponíveis: materiais de uso cotidiano dos pescadores, como as armadilhas de pesca da lagosta e as redes passaram por um processo de transformação estética e compunham $\mathrm{o}$ cenário.

A opção de realizar uma peça de Teatro Fórum também tem implicações em todo o trabalho, pois exigiu tempo e preparo do grupo para trabalhar com os imprevistos das intervenções na cena. É necessário destacar que a realização de um espetáculo de teatro fórum possui algumas especificidades:

Um dos princípios fundamentais do Teatro Fórum é realizar reflexões sobre as relações de poder, explorando histórias entre opressor e oprimido, onde o espectador assiste e participa da peça. A intervenção do público é que define o final da cena. Assim, o público deixa de ser espectador e se torna participante - espec-ator - apresentando alternativas para a questão debatida e se envolvendo na discussão do problema (BOAL, 1998, p. 53).

Assim, o público assiste à peça, que é reiniciada a partir da iniciativa do condutor da sessão de fórum, que é o curinga. $O$ curinga tem a função de estimular o público a participar do jogo. Ele convida os espectadores a entrarem em cena, substituindo o protagonista, e apresentarem alternativas para o desfecho da peça. O curinga debate com as pessoas presentes se as alternativas propostas podem ser efetivamente realizadas. $\mathrm{O}$ teatro fórum utiliza uma concepção de obra inacabada, nas palavras de Boal (2009, p.57) "No teatro - a mais complexa de todas as artes, porque a todos inclui com suas complexidades -, os artistas (cidadãos) devem fazer-nos ver que temos diante do nariz e não vemos, entender o que é claro e nos parece obscuro".

Após quase três meses de trabalho e convivência intensa com a comunidade Fernandeziana, no dia 06 de novembro de 2009, as 18:00 horas, com o pátio central da Escola Municipal Robinson Cruso lotado, o Grupo de Teatro do Oprimido Semilla Oceánica (contando com o apoio de um grupo de jovens 
músicos da ilha, com as mães das crianças e adolescentes), orgulhosamente apresentou: UNA MIRADA A LAS PROFUNDIDADES!

A peça ocorria nas profundidades do oceano Pacífico e contava a história de uma lagosta pequena - Hassus Linda que gostava de brincar de boneca com suas amigas. Certo dia, seu padrinho - Sr. Adulpo (um Polvo, o predador natural das lagostas) - a convidou para ir sozinha com ele até sua cova, pois queria lhe dar algo. Por gostar e confiar nele, ela o seguiu. Após este episódio algo mudou radicalmente em Linda: estava triste, cabisbaixa, nãoqueria brincar com suas amigas ou alimentarse. Sua mãe Langústia - após muito insistir que Linda contasse

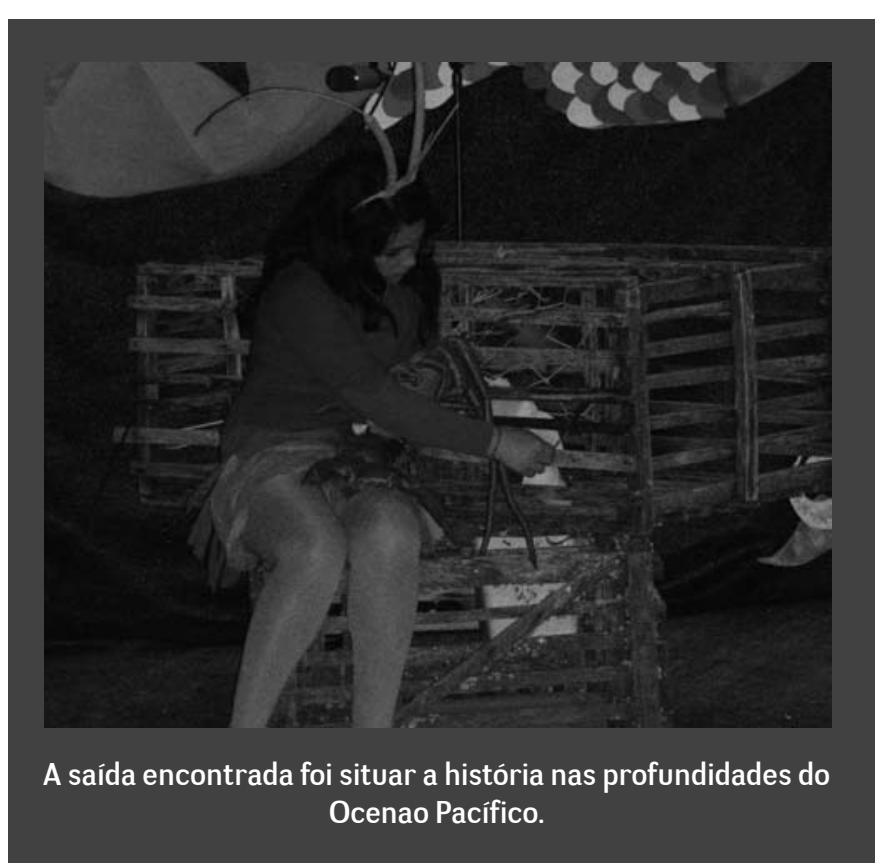

O Teatro do Oprimido coloca as opressões (tanto pessoais quanto sociais) no centro da encenação teatral, gerando com isso, a oportunidade das pessoas que participam dos espetáculos de TeatroFórum, avaliarem sua realidade criticamente, propondo soluções para mudanças, entrando em cena, dialogando sobre suas conclusões, sendovisto e vendo o outro, num processo deconstrução e transformação social. Essa metodologia mostra como a arte produzidapelohomem concreto, agente de suas ações e consciente delas, é um meio de mobilização social forte, porque mostra a desumanização das relações sociais e o que havia ocorrido, não acreditou quando ela lhe disse que seu padrinho tocou seu corpo de um modo muito feio, ruim. Mesmo gostando muito da filha, a mãe a repreende por mentir, inventar coisas deste tipo sobre seu padrinho que afinal a conhecia desde que nasceu, quando era ainda uma lagosta bebê. Linda busca fazer com que sua mãe acredite no que diz, porém sem sucesso. Explicita-se a crise, o impasse entre a mãe e a filha. A mãe retira-se pedindo à filha que pense bem, que reflita sobre a grave mentira que acabara de dizer sobre seu padrinho. Linda encontra-se no centro do palco, sozinha e amedrontada.

Naquele momento abriu-se o Fórum, o curinga retoma a coordenação dos trabalhos e instiga os espec-atores a entrarem em cena e mudarem o final da peça. Foram várias as intervenções do público, crianças e adultos que propunham alternativas para mudar o final de peça, desde a necessidade de pedir também desvenda as opressões explícitas e implícitas, gerando entendimento crítico sobre a realidade (BOAL, 2003, p. 43).

Durante quase três horas a comunidade entrou em cena e vivenciou as possibilidades de romper esta situação de opressão. Neste sentido, reafirmo:

as técnicas do teatro do oprimido facilitam atingir o imaginário da população porque criam representações do real e esta representação ao ser usada para discutir os problemas vividos e ensaiar jeitos de resolvê-los e superálos, contribui com a re-apropriação de sua cultura e desperta nos indivíduos, principalmente nos seus respectivos grupos sociais, o conceito de "cidadania plena", onde o indivíduo toma consciência de que ele não apenas vive em sociedade, mas a partir de suas ações, pode propor alternativas conscientes para transformá-la (BOAL, 2003, p. 44). 


\section{As marcas da experiência}

Desde a realização do trabalho na ilha, o exercício de olhar para o que realizamos, me faz perceber cada vez mais, a riqueza de todo o processo. Não foi sem angústia ou receio que vivi toda essa experiência, principalmente pelo cuidado que buscamos ter ao tratar de um tabu como o abuso sexual contra meninas, em uma comunidade tão pequena e distante de tudo.

Todo o processo foi vivido pelo grupo com dedicação e engajamento e a apresentação pública da peça foi um momento muito importante na ilha, pois foi a primeira vez que esta temática foi discutida publicamente, rompendo o silêncio de muitas décadas. Alguns relatos de participantes do grupo e de moradores de ilha, expressam isto:

\begin{abstract}
La obra que presentamos en el colegio me pareció un temazo y muí importante haber tocado este punto que nuestra comuna la ha manteniendo en silencio, por miedo. Es por esto que me siento orgulloso y contento que este grupo allá aceptado mostrar a la comunidad un tema tan delicado como el abuzo a menores (Pablo). ${ }^{5}$
\end{abstract}

Quiero también dejar por escrito lo contento que quede al finalizar la obra, debido al alto numero de intervenciones que se hizo en el momento de "la crisis", en la obra. En lo personal pensé que nadie iba a salir a intervenir, pero el publico sinceramente me sorprendió, y con este quedé satisfecho que el publico entro en la obra, cumpliendo con ello el $100 \%$ del objetivo del taller de teatro del oprimido (Daniella). ${ }^{6}$

Tendo como referência a estética do Teatro do Oprimido, foi possível discutir algumas situações de opressão,

5 Participante do grupo e líder juvenil da comunidade. Data do registro: 08 nov. 2009.

6 Médica da Comunidade e participante do COPRODE. Data do registro: 10 nov. 2009. oportunizando as crianças e jovens da ilha expressar-se e buscar alternativas para superá-la, tanto no plano individual, quanto coletivo, trazendo para o centro da "cena" e da vida diária, o plano de sua constituição como sujeitos de direitos, pois "o mundo é como é, não como gostaríamos que fosse: é preciso mudálo para que seja!" (BOAL, 2009, p. 59).

A distância estética no teatro permite que possamos ver com maior clareza as opressões e ensaiar soluções. Se o teatro é um espelho onde podemos ver nossos vício e virtudes, como afirmou Shakespeare, o Teatro do Oprimido pode ser um espelho mágico:

\begin{abstract}
Espelho que podemos invadir se não gostarmos da imagem que nos mostra e, ao penetrá-lo ensaiamos modificações desta imagem. Neste espelho, vemos o presente, mas podemos inventar o futuro dos nossos sonhos: o ato de transformar, é transformador - ao mudar nossa imagem, estaremos mudando a nós mesmos, para mudarmos depois o mundo (BOAL, 2003, p. 91).
\end{abstract}

A fala de uma das jovens do grupo expressa essa transformação:

Agradezco la oportunidad que me ha brindado la vida, me ha permitido derribar mis propios fantasmas y temores. Fue un desafío, difícil, pero a las vez muy gratificante. Esta es una oportunidad para $\mathrm{mi}$, para mi familia y para nuestra comunidad fernadeziana (Irene) ${ }^{7}$

Este processo começou na ilha e a possibilidade de constituição de um grupo de Teatro do Oprimido, bem como a disposição de seus habitantes em posicionarem-se a favor dos direitos das crianças e adolescentes nos inspira a apostar no caminho a ser percorrido. Como afirma o mestre: Mais importante que o tamanho do passo é a direção da caminhada (BOAL,1998, p. 76).

7 Participante do grupo de teatro. Data do registro: 08 nov. 2009. 


\section{Referências bibliográficas}

AUAD, D. Educando meninas e meninos: relações de gênero na escola. São Paulo: Contexto, 2006.

BOAL, Augusto. Teatro do Oprimido e outras poéticas políticas. Rio de Janeiro: Ed. Record, 1973.

. Jogos para atores e não atores. Rio de Janeiro: Ed. Record, 1998.

. O Teatro como arte marcial. Rio de Janeiro: Garamond, 2003.

A estética do Oprimido: reflexões errantes sobre o pensamento do ponto de vista estético e não cientifico. Rio de Janeiro: Garamond, 2009.

DELGADO-SCHENK; PETER, Janine. Derechos de los ninos em Chile - Informe Alternativo al Comitédelos Derechos del Niño de las Naciones Unidas sobre la aplicación de la Convención sobre los Derechos del Niño en Chile. OMCT/ OPCION - 2007. LOURO, Guacira Lopes. Uma leitura da história da educação sob a perspectiva do gênero. Projeto História: revista do Programa de Estudos Pós-Graduados em História e do Departamento de História da PUC- SP, São Paulo: EDUC, n. 11, p. 31-46, nov. 1994.

SCOTT, Joan. Gênero: uma categoria útil de análise histórica. Educação e Realidade, 20 (2), jul/dez, 1995, p. 71-99.

Sites:

www.ctorio.org.br. Acesso em: 26 jun. de 2010. 